\title{
INFLUENCE OF POLYLACTIDE MODIFICATION WITH BLOWING AGENTS ON SELECTED MECHANICAL PROPERTIES
}

\author{
Aneta Tor-Świątek ${ }^{1}$, Tomasz Garbacz ${ }^{1}$, Vladimir Sedlarik², Petr Stloukal², Pavel Kucharczyk ${ }^{2}$ \\ 1 Lublin University of Technology, Faculty of Mechanical Engineering, Department of Technology and Polymer \\ Processing, 36 Nadbystrzycka St. 20-618 Lublin, e-mail: a.tor@pollub.pl, t.garbacz@pollub.pl \\ 2 Centre of Polymer Systems, Tomas Bata University in Zlin, tr. T. Bati 5678, 76001 Zlin, Czech Republic, e-mail: \\ sedlarik@cps.utb.cz
}

Received: 2017.10.16

Accepted: 2017.11.01

Published: 2017.12.05

\begin{abstract}
The article presents research of modification of PLA with four types of blowing agents with a different decomposition characteristic. Modifications were made in both cellular extrusion and injection molding processes. The obtained results show that dosing blowing agents have the influence on mechanical properties and structure morphology. Differences in the obtained results are also visible and significant between cellular processes.
\end{abstract}

Keywords: polylactide, blowing agent, extrusion, injection molding.

\section{INTRODUCTION}

Modification of polymeric materials is intended to give the products specific properties or, in case of hard to recycle materials, facilitate their processing. The modification process involves changing the technological conditions of the manufacturing process, the processing tools as well as the addition of auxiliary materials such as fillers, plasticizers and stabilizers. The aids can be divided into two main groups: processing and functional. Group of processing agents are processing stabilizers and processing modifiers. Functional agents include properties stabilizers and property modificators [3, 11, 12].

Functional modifiers are primarily property stabilizers that prevent undesired behavior of the material during its further use. The properties stabilizers include, among others, anti-aging agents that prevent the release of harmful disintegrants, metal deactivators, anti-aging electric cables and hydrodesistant stabilizers, prevent water effect $[2,9]$.

A large separate group is property modifiers. They enable changing optical, mechanical, surface, flammability properties.
Modifiers include also porous and microporous blowing agents (porophors). Their main ingredient is gas, which, under appropriate conditions of the process, expands, resulting in porosity. The obtained product changes its structure from solid to porous. Mold the material so that the separated gas can be cooled down and concentrate the microporous material. This modifier affects many properties such as density, hardness, elasticity, tensile strength, stiffness $[7,8,10,14,15]$.

Modification with the use of the blowing agents can be carried out using two main processes of plastics processing i.e. extrusion $[4,11$, 12] and injection [1, 5, 6, 13]. In both cases, it is important to choose the type and quantity of the dosing blowing agent, and thus the conversion of processing parameters taking into account the characteristics and max. decomposition temperature of the agent.

\section{EXPERIMENTAL}

During research polylactide (PLA) with trade name NatureWorks Ingeo 2002D was used. According to the producer data PLA characterises 


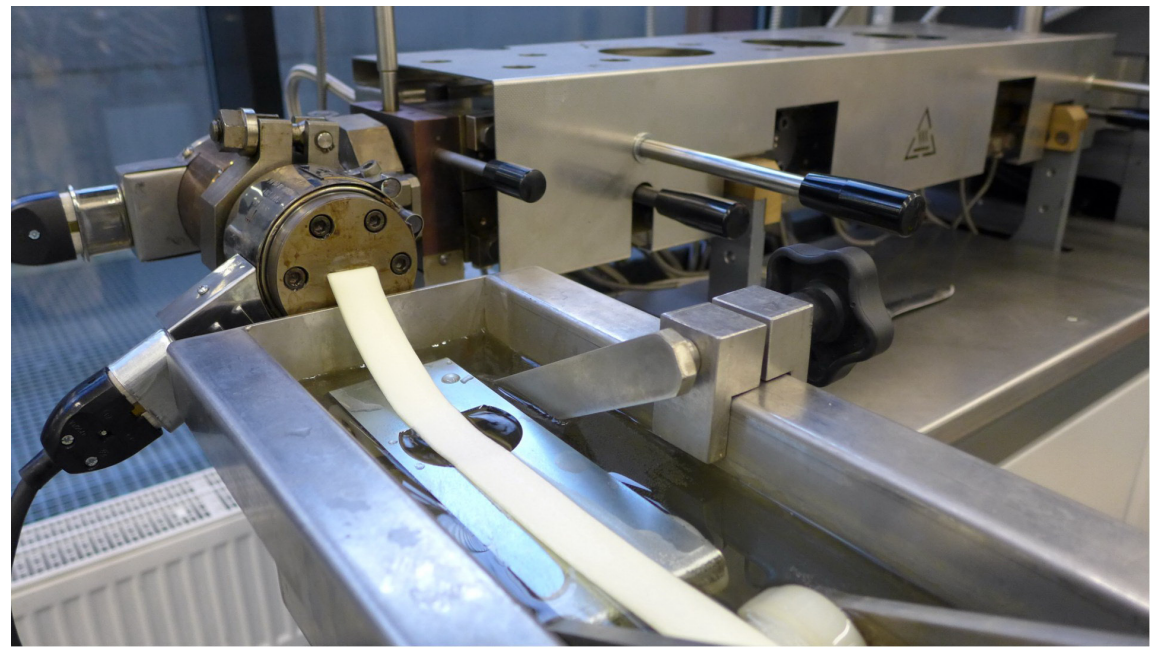

Fig. 1. View of technological line for cellular extrusion; head with a die for tape producing, and with the tape produced, PLA $+3 \%$ Expancel $950 \mathrm{MB}$

MFR $\left(210^{\circ} \mathrm{C} ; 2,16 \mathrm{~kg}\right): 5-7 \mathrm{~g} / 10 \mathrm{~min}$; tensile strength: 7,7 MPa; yield stress: 8, $7 \mathrm{MPa}$; Young modulus: $500 \mathrm{MPa}$; elongation: $6.0 \%$; impact by Izod: $0.24 \mathrm{~J} / \mathrm{m}$; color: transparent. Polylactide was modified with selected blowing agents with different decomposition characteristic.

In the experiments, various types of chemical blowing agents were used: Expancel $950 \mathrm{MB}$ manufactured by Akzo Nobel, Hydrocerol 530, Hydrocerol ITP 810, manufactured by Clariant Masterbatches GmbH and LyCell-F017 manufactured by $\mathrm{Ly}-\mathrm{TeC} \mathrm{GmbH}$.

Hydrocerol 530 is an exothermic blowing agent with nucleating properties. It comes in a granular form, with the diameter of spherical grains ranging from 2.4 to $2.8 \mathrm{~mm}$. In order to obtain high foaming process efficiency, the processing temperature should range between 120$170^{\circ} \mathrm{C}$. Active substances in this blowing agent constitute a mixture of appropriately proportioned chemical compounds such as azodicarbonamide.

LyCell-F017 is an endothermic blowing agent. It has the form of pellets with a diameter ranging from 1.2 to $1.8 \mathrm{~mm}$ and a length from
2.3 to $2.5 \mathrm{~mm}$. This blowing agent is a mixture of sodium acid carbonate and 2-hydroxypropanetricarboxylic acid (citric acid).

Expancel $950 \mathrm{MB}$ is a blowing agent that has a form of spherical thermoplastic polymer capsules (microspheres) that contain a hydrocarbon gas. This is an endothermic blowing agent. Expancel microspheres do not bond because the capsules retain their blocking properties, which pre-vents release of the constrained gas. Expancel $950 \mathrm{MB}$ is a mixture that contains $65 \%$ microspheres in the copolymer of ethylene and vinyl acetate (EVA).

The decomposition products of the applied blowing agents mainly include carbon dioxide $\mathrm{CO}_{2}$, a small amount of water $\mathrm{H}_{2} \mathrm{O}$ and nitrogen $\mathrm{N}_{2}$. Selected properties of the discussed blowing agents are listed in Table 1.

Based on the adopted research program, polymeric material for cellular extrusion and cellular injection molding was modified in such a way that the blowing agents were fed into it during the mechanical mixing process. The blowing agents used in the cellular processes were fed into the polymers being processed in the following quan-

Table 1. Selected properties of blowing agents used in the cellular injection molding process

\begin{tabular}{|l|l|c|c|c|c|}
\hline No. & Characteristic quantity & Ly-Cell F017 & Hydrocerol 530 & Hydrocerol ITP810 & Expancel 950 MB \\
\hline 1 & Distribution & Endothermic & Exothermic & Endothermic & Microspheres \\
\hline 2 & Decomposition initiation, ${ }^{\circ} \mathrm{C}$ & 155 & 170 & 160 & 130 \\
\hline 3 & Processing temperature, ${ }^{\circ} \mathrm{C}$ & $170-210$ & $170-190$ & $160-180$ & $130-190$ \\
\hline 4 & Dosage, $\%$ & $0.5-2.0$ & $0.5-2.0$ & $1.0-5.0$ & $0.5-2.5$ \\
\hline
\end{tabular}


Table 2. Research results of the mechanical properties of the injection molded parts of PLA, average values given with accuracy $1 \mathrm{MPa}$

\begin{tabular}{|c|c|c|c|c|c|c|}
\hline No. & Blowing agent type & $\begin{array}{l}\text { Blowing agent content } \\
\%\end{array}$ & $\begin{array}{c}\text { Tensile strength } \\
\sigma_{\mathrm{m}}, \mathrm{MPa}\end{array}$ & $\begin{array}{l}\text { Yield strength } \\
\sigma_{\mathrm{B}}, \mathrm{MPa}\end{array}$ & $\begin{array}{c}\text { Youngs modulus } \\
\text { E, MPa }\end{array}$ & $\begin{array}{c}\text { Elongation at break } \\
\varepsilon, \%\end{array}$ \\
\hline 1 & PLA solid & 0 & 70 & 62 & 3300 & 2.80 \\
\hline 2 & \multirow{3}{*}{ Expancel 950 MB } & 0.5 & 50 & 45 & 3220 & 2.10 \\
\hline 3 & & 1.5 & 42 & 40 & 3150 & 1.85 \\
\hline 4 & & 3.0 & 40 & 37 & 3200 & 1.50 \\
\hline 5 & \multirow{3}{*}{ Hydrocerol 530} & 0.5 & 62 & 52 & 3230 & 2.50 \\
\hline 6 & & 1.5 & 58 & 48 & 3280 & 2.30 \\
\hline 7 & & 3.0 & 48 & 41 & 3100 & 2.20 \\
\hline 8 & \multirow{3}{*}{ Hydrocerol ITP810 } & 0.5 & 64 & 48 & 3230 & 2.60 \\
\hline 9 & & 1.5 & 62 & 48 & 3150 & 2.60 \\
\hline 10 & & 3.0 & 54 & 52 & 3000 & 2.40 \\
\hline 11 & \multirow{3}{*}{ Ly-Cell F017 } & 0.5 & 65 & 53 & 3170 & 2.90 \\
\hline 12 & & 1.5 & 62 & 47 & 3080 & 2.90 \\
\hline 13 & & 3.0 & 58 & 48 & 3050 & 2.80 \\
\hline
\end{tabular}

tities: $0.5 \%, 1.5 \%$ and $3 \%$ by mass $(\mathrm{w} / \mathrm{w})$. In order to obtain high process efficiency for the above blowing agents, the processing temperature range was $160 \div 185^{\circ} \mathrm{C}$.

The experimental tests were conducted on a laboratory technological line for profile extrusion, its main component being a double-screw extruder EHP 2x20 Sline (Fig. 1), produced by Zamak Mercator (Poland). The extruder's plasticizing unit had four heating zones, the screw had an $\mathrm{L} / \mathrm{D}$ ratio of 25 and an outside diameter, $\mathrm{D}$, of $20 \mathrm{~mm}$. The rotational speed of the extruder screw ranged from 0 to $200 \mathrm{rpm}$ and was adjusted continuously. The technological line also consisted of a head for profile extrusion. The head had a replaceable extruder die to enable extrusion of profiles with different sizes and shapes, both symmetric and asymmetric.

Used for tape profile extrusion, the extruder die had a width of $15.5 \mathrm{~mm}$ and a height of 2.0 $\mathrm{mm}$. The extruder head was made up of two heating zones and two corresponding ring-shaped heaters mounted on the head body. The extrusion line also consisted of a cooling device that had a length of $1740 \mathrm{~mm}$, width of $220 \mathrm{~mm}$ and depth of $200 \mathrm{~mm}$. In the tests, we also used a belt hauloff; the belt had a width of $100 \mathrm{~mm}$ and a length of $2000 \mathrm{~mm}$.

The extrusion process was carried out under the developed and imposed conditions, set in the extrusion process line. They included the following: temperature values of heating zones in the plasticizing unit were respectively: $125,140,150$,
$160,165,175,180$ and $195^{\circ} \mathrm{C}$; temperature values in the head for the three heating zones were respectively: 190,175 and $165^{\circ} \mathrm{C}$. The determined rate of screw rotation was altered within the range of 50-100 rpm). Temperature of the cooling agent was $12 \div 14^{\circ} \mathrm{C}$.

PLA modification was also made in injection molding process with the use of the same blowing agents (Table 1). The test stand consists of a screw injection molding machine, Arburg AllRounder $320^{\circ} \mathrm{C}$, equipped with an injection mold, as shown in Figure 2. The machine has a single-screw plasticizing system, with a screw diameter of $36 \mathrm{~mm}$. A moveable subassembly of the injection mold is mounted to the moveable table of the machine, in which two mold cavities are located. The mold cavity has the shape and

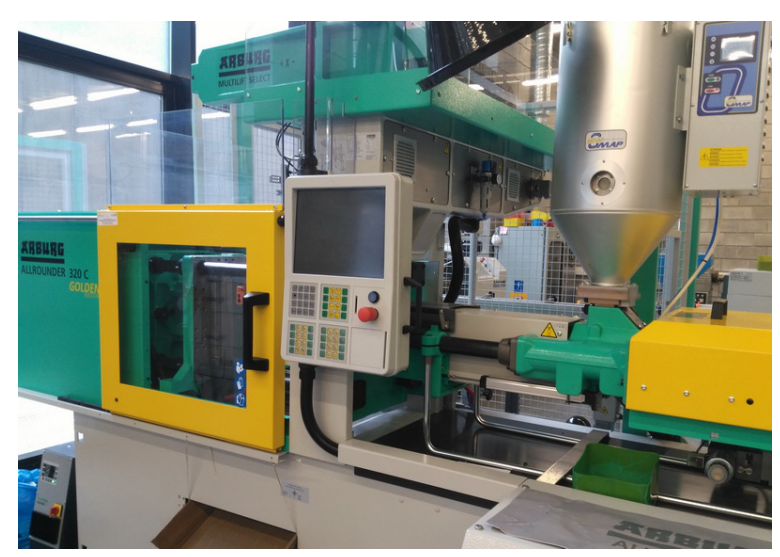

Fig. 2. Test stand used in the experiments - injection molding machine Arburg AllRounder 320C 
Table 3. Research results of the mechanical properties of the extruded parts of PLA, average values given with accuracy $1 \mathrm{MPa}$

\begin{tabular}{|c|c|c|c|c|c|c|}
\hline No. & Blowing agent type & $\begin{array}{l}\text { Blowing agent content } \\
\%\end{array}$ & $\begin{array}{c}\text { Tensile strength } \\
\sigma_{\mathrm{m},} \mathrm{MPa}\end{array}$ & $\begin{array}{l}\text { Yield strength } \\
\qquad \sigma_{\mathrm{B}}, \mathrm{MPa}\end{array}$ & $\begin{array}{c}\text { Youngs modulus } \\
\mathrm{E}, \mathrm{MPa}\end{array}$ & $\begin{array}{c}\text { Elongation at break } \\
\varepsilon, \%\end{array}$ \\
\hline 1 & PLA solid & 0 & 60 & 55 & 2700 & 4.00 \\
\hline 2 & \multirow{3}{*}{ Expancel $950 \mathrm{MB}$} & 0.5 & 55 & 55 & 2500 & 3.70 \\
\hline 3 & & 1.5 & 44 & 38 & 2450 & 2.80 \\
\hline 4 & & 3.0 & 35 & 35 & 1850 & 5.50 \\
\hline 5 & \multirow{3}{*}{ Hydrocerol 530} & 0.5 & 26 & 26 & 1900 & 2.00 \\
\hline 6 & & 1.5 & 25 & 25 & 1650 & 2.50 \\
\hline 7 & & 3.0 & 27 & 27 & 1900 & 2.50 \\
\hline 8 & \multirow{3}{*}{ Hydrocerol ITP810 } & 0.5 & 25 & 25 & 1850 & 2.0 \\
\hline 9 & & 1.5 & 28 & 28 & 1940 & 3.0 \\
\hline 10 & & 3.0 & 25 & 25 & 1850 & 2.30 \\
\hline 11 & \multirow{3}{*}{ Ly-Cell F017 } & 0.5 & 45 & 45 & 2000 & 4.50 \\
\hline 12 & & 1.5 & 45 & 45 & 2200 & 4.50 \\
\hline 13 & & 3.0 & 50 & 50 & 3000 & 4.00 \\
\hline
\end{tabular}

dimensions of a tensile specimen for static tension tests, the so-called specimen type II [26], shown in Figure 3.

The mold cavity dimensions are as follows: length $150 \mathrm{~mm}$, width from 10 to $20 \mathrm{~mm}$, thickness $4 \mathrm{~mm}$. Directly in the mold cavities there are point ejector pins mounted, with a diameter of $6 \mathrm{~mm}$. In the fixed subassembly of the mold, there are flow system channels which supply the polymeric material to the mold cavities; the channels have a direct contact with an injection nozzle of the plasticizing system.

The following parameters of the cellular injection molding process were adopted: injection and clamping time - 2 seconds; molded piece cooling time - $30 \mathrm{~s}$, temperature of thermostated mold - $19 \pm 1{ }^{\circ} \mathrm{C}$. Injection molding machine All-

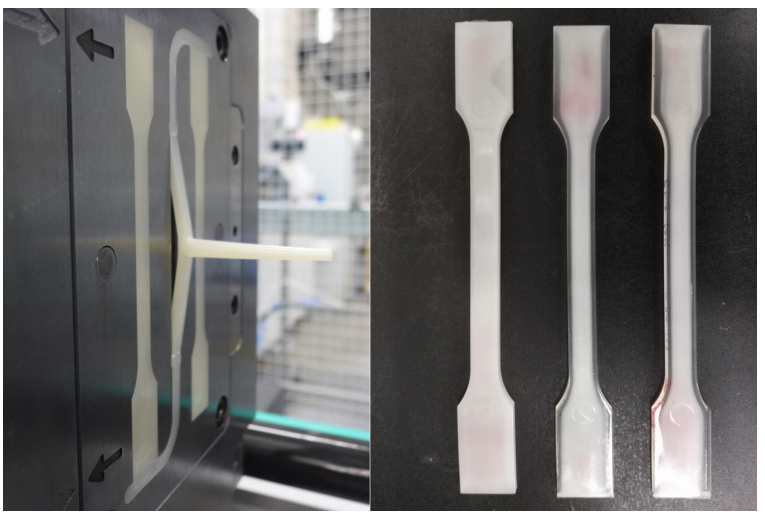

Fig. 3. Porous PLA injection molded parts with an ingot and molded part, PLA $+0,5 \%$ Ly-Cell F017
Rounder $320^{\circ} \mathrm{C}$ do not have possibility to direct control and readout of injection pressure and counter-pressure. The value specifying the injection pressure is the pressure in the hydraulic system, aimed at testing the value of - $5 \mathrm{MPa}$. In the experiments, the temperatures of the polymers being investigated were set in the particular heating zones of the plasticizing system in the following way: in zone I $160^{\circ} \mathrm{C}$, in zone II $-170^{\circ} \mathrm{C}$, III $-180^{\circ} \mathrm{C}, \mathrm{IV}-185^{\circ} \mathrm{C}$.

In the framework of research program tensile strength and elongation at break were measured. The research of mechanical properties was made on tensile machine Zwick/Roel Z010 according to PN-EN ISO 527-1:1998 and PN-EN ISO 1798:2001. Strength properties of the injection molded parts under static tension were determined using a testing machine manufactured by Zwick Z010. The machine was equipped with $10 \mathrm{kN}$ screw wedge chucks together with the accessories. The measurements were done at a tensile speed of $10 \mathrm{~mm} / \mathrm{min}$ and under the measuring load range $0 \div 500 \mathrm{~N}$. The applied shape and dimensions of the specimens complied with the relevant norm. The specimen thickness corresponded to the injection molded part thickness and it was measured and registered each time together with the width of the measuring length right before the tests.

The structure observations of the extrudate was made in passing light on metallographic microscope Nikon ECLIPSE LV100ND with DSU3 Digital Camera Control Unit. 


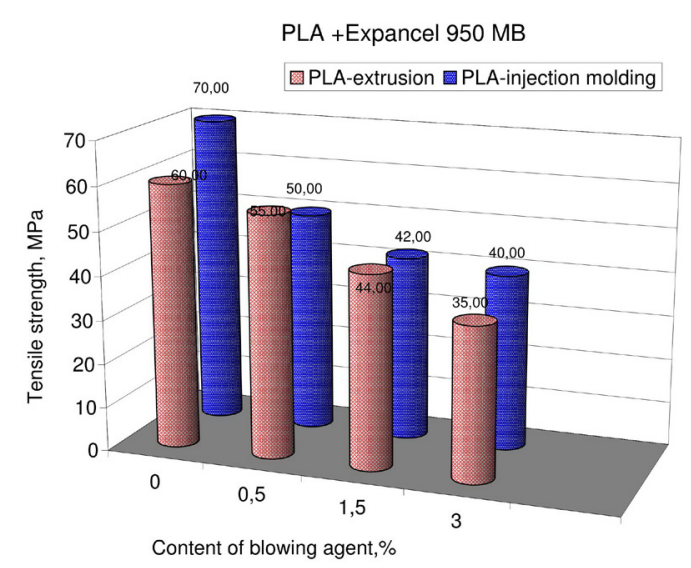

Fig. 4. Dependence of tensile strength of the PLA extruded and injection molded parts on the content of microspheres Expancel $950 \mathrm{MB}$

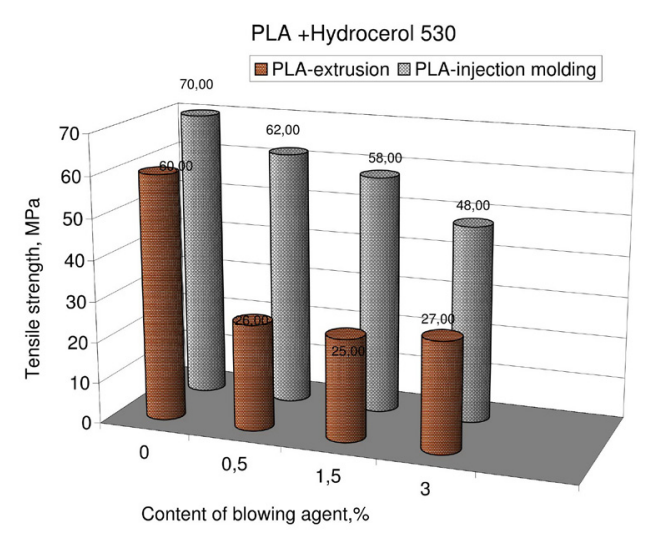

Fig. 6. Dependence of tensile strength of the PLA extruded and injection molded parts made on the content of exothermic blowing agent Hydrocerol 530

\section{RESULTS AND DISCUSSION}

The results of determining selected mechanical properties of the injection molded and extruded parts, obtained at different contents of the blowing agent in the polymers being processed are shown in Table 2 and 3 and Figures 5-8.

With increased content of blowing agent in the injected material the value of the yield strength decreases. Elongation at break decreases monotonically, non-linearly, over the range increasing content of blowing agent. This relationship is similar for each of the materials and blowing agents.

It has been observed that increasing the blowing agent content in the extruded product decreases the value of tensile strength in a non-linear manner in the whole content range of the blowing agent in the polymer.

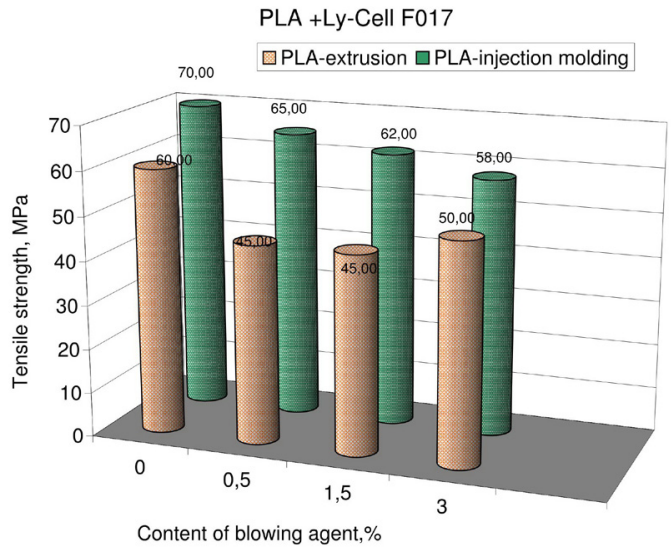

Fig. 5. Dependence of tensile strength of the PLA extruded and injection molded parts made on the content of endothermic blowing agent Ly-Cell F017

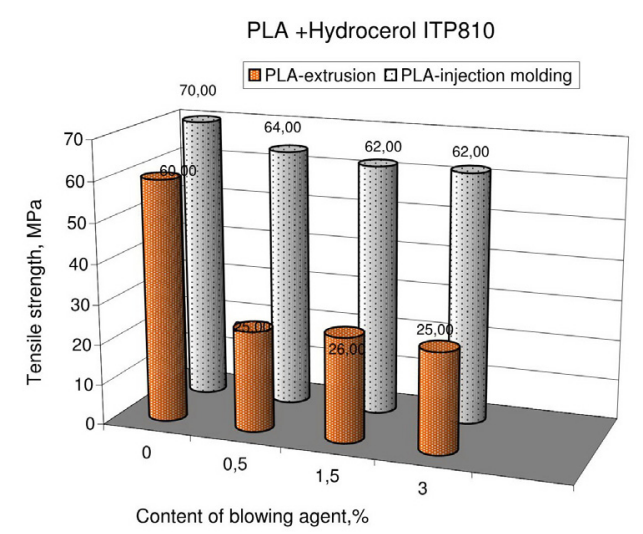

Fig. 7. Dependence of tensile strength of the PLA extruded and injection molded parts made on the content of endothermic blowing agent Hydrocerol ITP810

Significant differences in mechanical strength of the porous, both extruded and injection molded parts, can be observed. For example, the blowing agent Hydrocerol 530 (Fig. 7), with the endothermic decomposition characteristics, dosed in the range from 0 to $3.0 \%$ causes a decrease in tensile strength by $55 \%$ in extruded part and about $30 \%$ in injected parts. In the case of polylactide with $3 \%$ content of blowing agent LyCell F017 (Fig. 6) the tensile strength decrease average $16 \%$ in extruded parts and $17 \%$ in injected parts.

The blowing agent was dosed in $0.5-3.0 \%$ by weight, so as to produce extrudate and injection molding with a solid surface and a cellular core. The shape and outside dimensions of the product agree with shape and dimensions of solid products made of the tested PLA. 

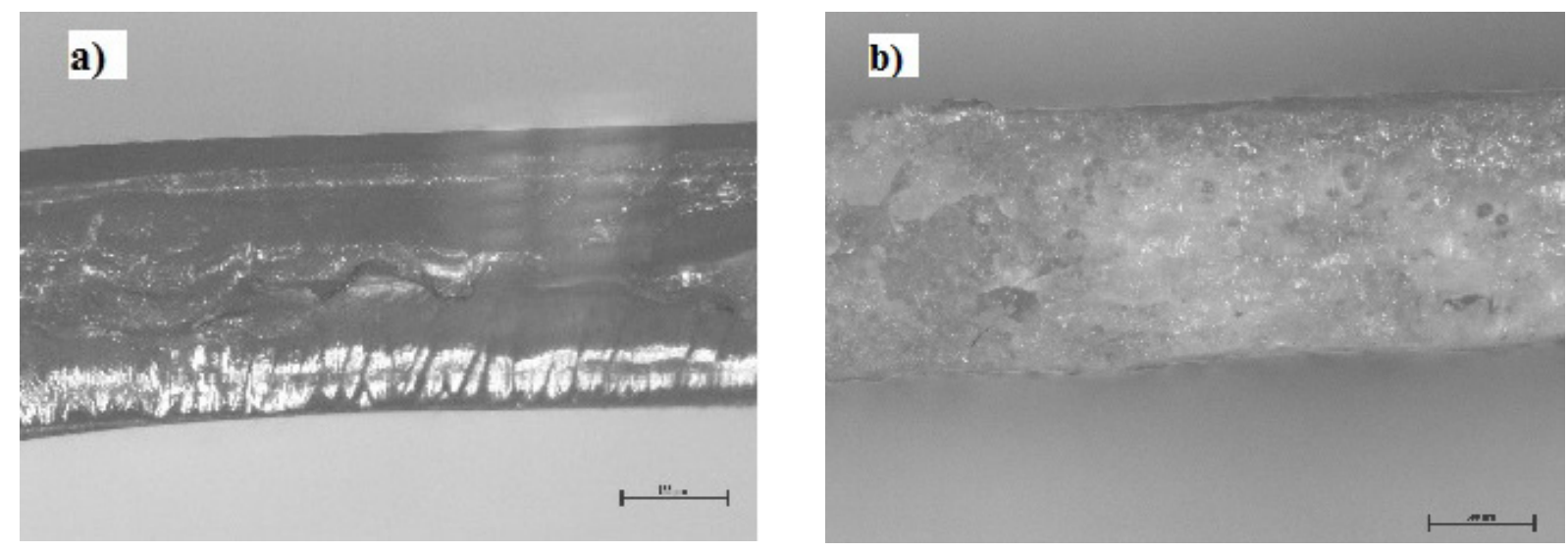

Fig. 8. Fragment of the cross section of the extruded PLA: a) solid, b) with $3 \%$ microspheres Expancel $950 \mathrm{MB}$
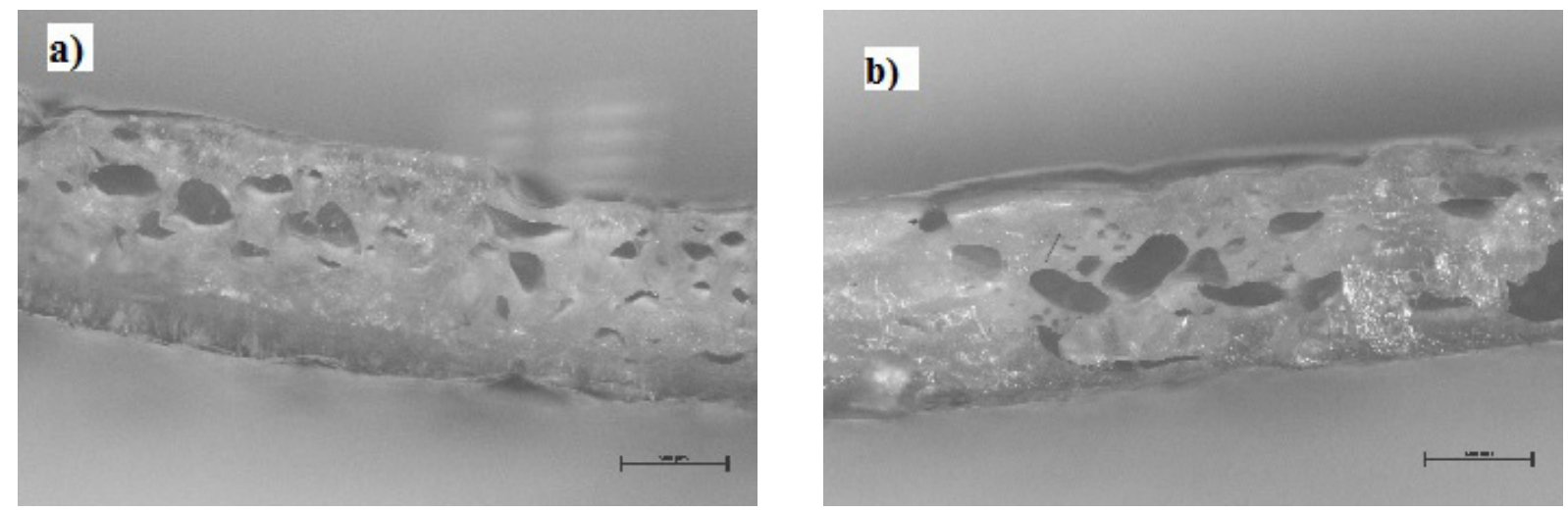

Fig. 9. Fragment of the cross section of the extruded PLA: a) with 1.5\% Hydrocerol 530,

b) with $3 \%$ Hydrocerol 530
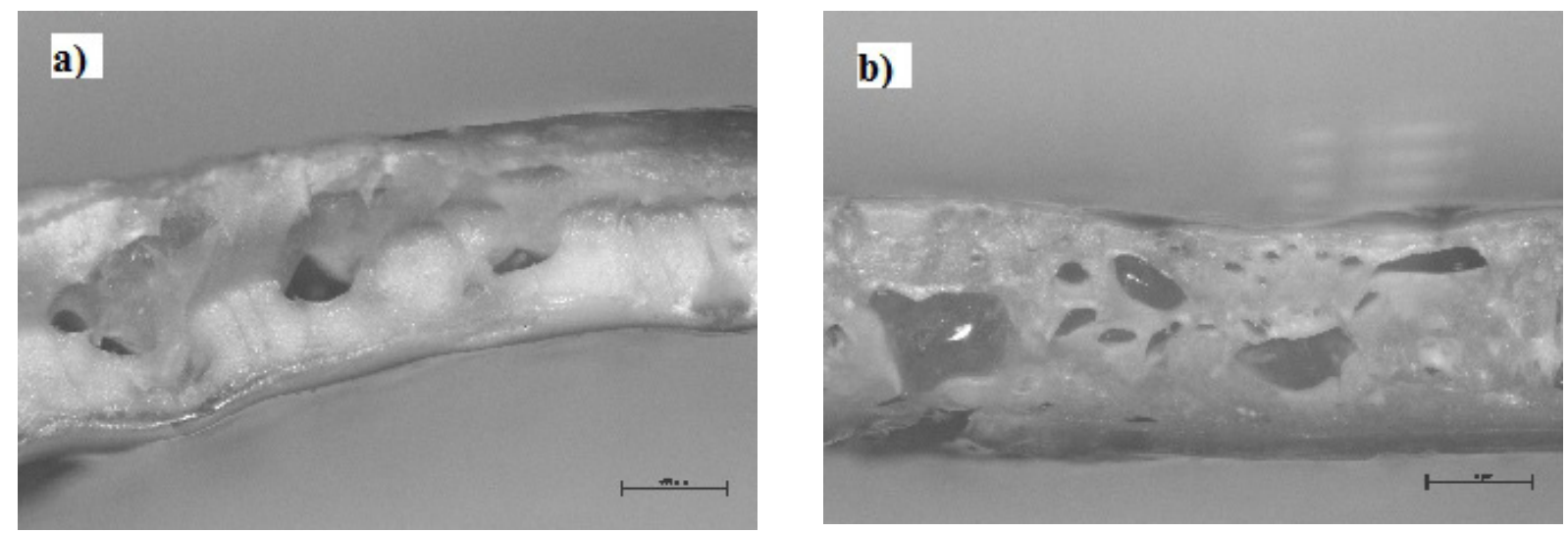

Fig. 10. Fragment of the cross section of the extruded PLA: a) with 3\% Ly-Cell F017,

b) with $3 \%$ Hydrocerol ITP 810

The macroscopic structure of the produced cellular tapes was examined at the stand for polymer cellular structure image analysis. The stand comprised a metallographic, optical image recording devices and a computer equipped with specialist software. Examples of the cellular structure extruded and injected parts are shown in Figures from 9 to 13. The morphology shows, that extruded samples (Fig. 8-10) are porous in whole cross section area. There is no solid outer layer visible, as in the case of injection molded samples. Obtained pores have different size and 

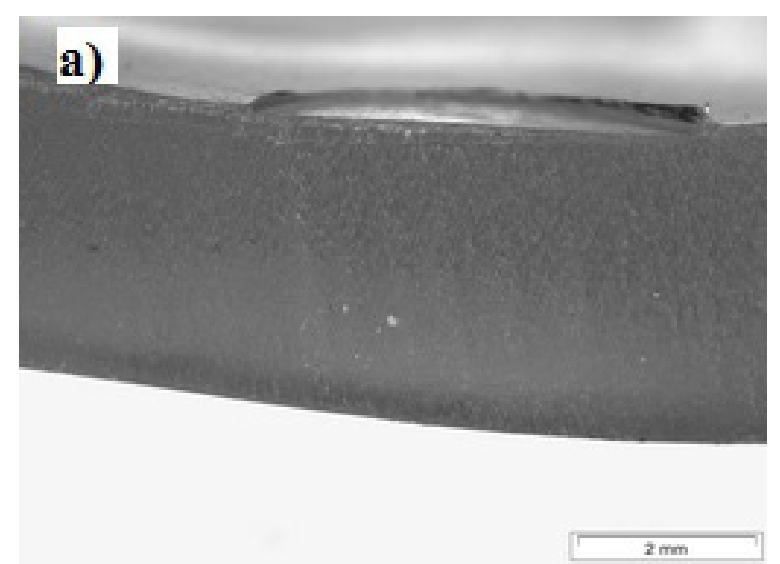

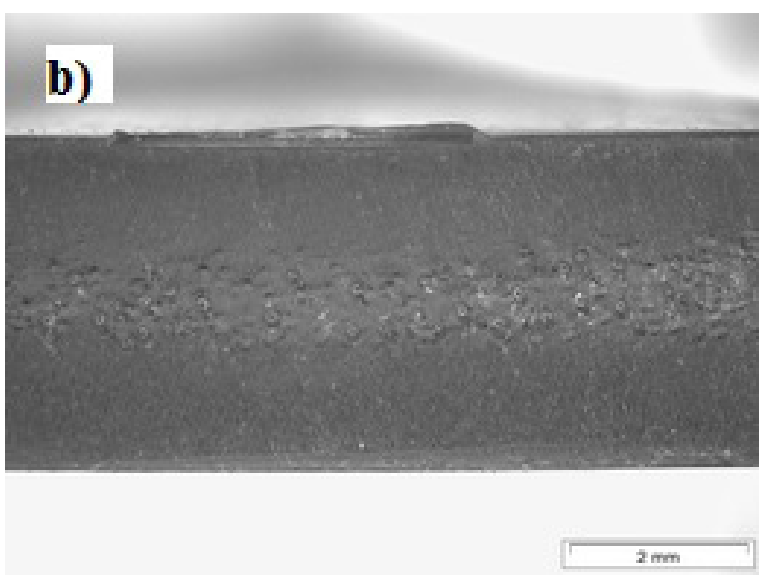

Fig. 11. Fragment of the cross section of the injected PLA: a) solid, b) with $0.5 \%$ Hydrocerol ITP810
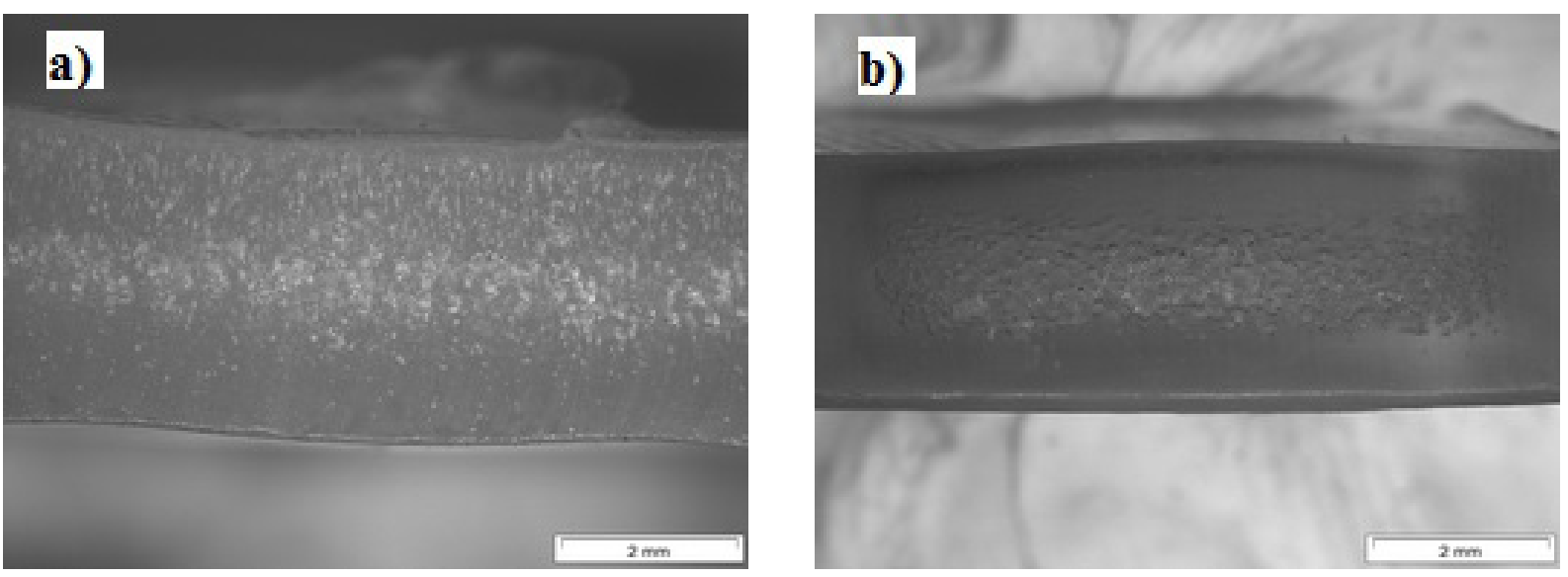

Fig. 12. Fragment of the cross section of the injected PLA: a) with 1.5\% microspheres Expancel $950 \mathrm{MB}$,

b) with $3 \%$ Hydrocerol 530
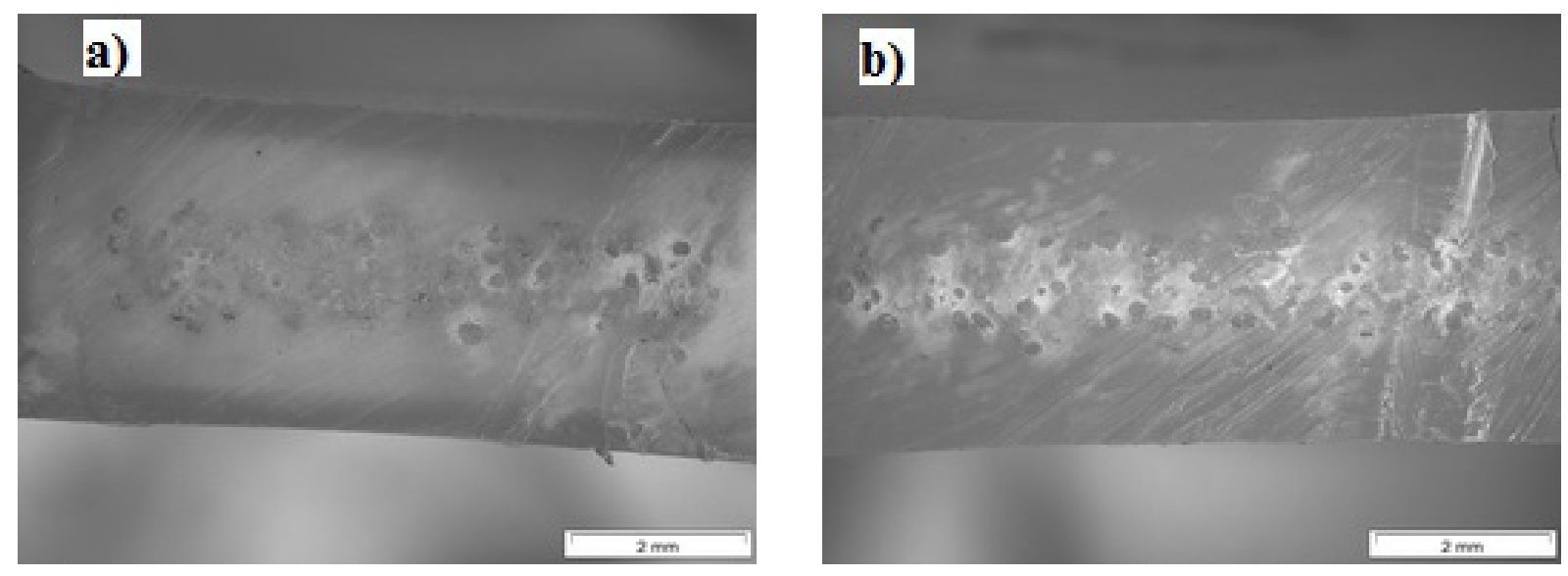

Fig. 13. Fragment of the cross section of the injected PLA: a) with $0.5 \%$ Ly0Cell F017,

b) with $1.5 \%$ Ly-Cell F017

shape. The closer to the core the solid outer layer it is, the more the pore size increases (Fig. 9, 10).

A discernible effect of the blowing agent used, its type and effect characteristics on the ob- tained morphology of porous molded pieces were observed. Based on the analysis of the photographs taken, it has been found that the injection molded parts with $0.5 \%$ content of the blowing 
agent (Fig. 11-13) have a clearly visible solid outer layer and their pore distribution is non-uniform to the greatest extent.

The change in the number of pores and their surface quantity in the cross section of the molded parts can also depend on cooling intensity. Fast cooling hampers the occurrence and growth of the pores, especially of those located closer to the surface layer (Figs. 12, 13). In the case of the porous parts produced using the blowing agent with the endothermic decomposition characteristics, the gas release in the course of processing comes to an end once the energy supply is stopped. The obtained porous structure is uniform; the pores have a spherical or quasi spherical shape. The pores have similar sizes, irrespective of their location in the product.

\section{CONCLUSIONS}

The tensile strengths results shown in the work are strongly dependent on the characteristics of the blowing agent used. Agent added to a $3 \%$, irrespective of the characteristics of its activity, it con-tributes to a significant deterioration in the strength properties of the tested PLA compositions.

The porous structure is an advantage of extrusion and injection molded parts as it results in a decreased amount of the polymeric composite needed in their production. Owing to the use of chemical blowing agents, porous parts have, among others, lower weight, enhanced damping properties, and lower processing shrinkage. The cellularity determines the gaseous phase content in a cellular product, determining at the same time the density decrease value of this product. Such content of the blowing agent in the polymer determines both the coating continuity over the whole cross section and the uniform distribution of pores and their similar sizes.

There was also a significant influence of the type of processing and technological conditions on the obtained mechanical strength values of the tested PLA compositions. In the extrusion process, the extruded profile is freely extruded and its cooling is carried out directly in the water in the cooling bath. The reason for this is the formation of a product having a porous structure in the whole area, also in the top layer. In the injection molding process, the polymer compositions are cooled in a closed injection mold. Indirect cooling of the composition, as a result of its contact with the cold surfaces of the injection mold cavities, results in the formation of products having a broad solid top layer and a porous core. This results in reduced strength properties extruded compositions compared to injection molded compositions. The change in strength properties of the same PLA composition obtained in such different processing processes is up to $50 \%$.

The strength properties discussed in the paper depend to a great extend also on the characteristics of the blowing agent used. This is largely due to thermal properties of the polymeric materials being used and the effect of the blowing agents on the polymeric materials used in the process. However, such a dependence has not been thoroughly investigated yet and will, therefore, be a subject of further studies.

\section{REFERENCES}

1. Bociąga E., Palutkiewicz P. The influence of injection moulding parameters and blowing agent addition on selected properties, surface state and structure of HDPE parts. Polymer Engineering and Science, 4 (53), 2013, 679-704.

2. Jachowicz T., Gajdoš I.: Effect of natural ageing on some properties of oxybiodegrading agent-containing polypropylene products. Przemysl Chemiczny, 11 (93) 2014, 1983-1885.

3. Klepka T., Jeziórska R. and Szadkowska A. Cienkościenne wyroby z modyfikowanego polietylenu dużej gęstości. Przemysł Chemiczny, 8, 2015, 1352-1355.

4. Garbacz T.: Structure and properties of cellular thin-walled cable coatings. Polimery 11-12 (57), 2012, 91-94.

5. Garbacz T., Palutkiewicz P.: Effectiveness of blowing agents in cellular injection molding. Cellular Polymers 4 (34), 2015, 189-214.

6. Guo M.C., Heuzey M.C., Carreau P.J.: Cell structure and dynamic properties of injection molded polypropylene foams. Polymer Engineering and Science, 47, 2007, 1070-1081.

7. Matuana L. M., Park C. B., Balatinecz J. J.: Structures and mechanical properties of microcellular foamed polyvinyl chloride. Cellular Polymers, 17, 1998, 1-16.

8. Rizvi S.J.A., Bhatnagar N.: Microcellular PP vs. microcellular PP/MMT nanocomposites: A comparative study of their mechanical behavior. International Polymer Processing, 26, 2011, 375-382.

9. Stloukal P., Kucharczyk P. Acceleration of polylactide degradation under biotic and abiotic con- 
ditions through utilization of a new, experimental, highly compatible additive. Polymer Degradation And Stability, 142, 2017, 217-225.

10. Tejeda E.H., Sahagún C.Z., González-Núñez R., Rodrigue D.: Morphology and mechanical properties of foamed polyethylene-polypropylene blends. Journal of Cellular Plastics, 41, 2005, 417-435.

11. Tor-Swiatek A. Evaluation of the effectiveness of the microcellular extrusion process of low density polyethylene. Eksploatacja I Niezawodnosc-Maintenance and Reliability, 3 (15), 2013, 225-229.

12. Tor-Swiatek A. Characteristics of physical structure of poly(vinyl chloride) extrudate modified with microspheres. Polimery, 7-8 (57), 2012 , 577-580.

13. Turng LS, Kharbas H.: Development of a hybrid solid-microcellular co-injection molding process. International polymer processing, 19, 2004, 77-86.

14. Velasco J. I., Antunes M., Ayyad O., Saiz-Arroyo C., Rodríguez-Pérez M. A., Hidalgo F., de Saja, J A..: Foams based on low density polyethylene/ hectorite nanocomposites: Thermal stability and thermo-mechanical properties. Journal of Applied Polymer Science, 105, 2007, 1658-1667.

15. Zhou Q., Chuan-Bo C.: Exo-endothermic blowing agent and its blowing behavior. Journal of Cellular Plastics, 41, 2005, 225-234. 